\title{
Desenvolvimento fenológico e agrônomico de três híbridos de milho em três épocas de semeadura
}

\author{
Agronomic and phenological development of three maize hybrids at three sowing dates
}

\author{
Everton Leonardo Forsthofer ${ }^{1}$ Paulo Regis Ferreira da Silva ${ }^{2}$ Gilber Argenta ${ }^{3}$ \\ Mércio Luiz Strieder ${ }^{4}$ Elias Suhre $^{4}$ Lisandro Rambo $^{5}$
}

\section{RESUMO}

As variações nas condições ambientais determinadas pelas diferentes épocas de semeadura exercem grande influência sobre a cultura do milho. Objetivando avaliar a fenologia e o desenvolvimento de três híbridos de milho, em três épocas de semeadura, conduziu-se um experimento na estação de crescimento 2000/01, na região da Depressão Central do Rio Grande do Sul. Avaliaram-se os híbridos simples Pioneer 32R21, de ciclo superprecoce, Dekalb 214, de ciclo precoce, e o híbrido duplo Agroceres 1051, de ciclo normal, em três épocas de semeadura: 22/08/2000 (cedo), $31 / 10 / 2000$ (intermediária) e 25/01/2001 (tardia), sob condições naturais de precipitação pluvial. A duração dos subperíodos de desenvolvimento em todos os híbridos diminuiu com o atraso da semeadura. As diferenciações do pendão e da espiga ocorreram, respectivamente, nos estádios de 6 - 7 e 10 - 11 folhas completamente expandidas, independente do ciclo do híbrido e da época de semeadura. A taxa de emissão de folhas foi maior na semeadura de outubro e no híbrido de ciclo superprecoce. A área foliar por planta foi menor na semeadura mais tardia, aumentando com o incremento do ciclo do híbrido. O número de espiguetas por espiga, o rendimento de grãos $e$ o peso do grão foram geralmente maiores na semeadura de outubro em relação aos das semeaduras de agosto e de janeiro.

Palavras-chave: Zea mays, práticas culturais, fenologia.

\section{ABSTRACT}

Variations in environmental conditions determined by different sowing dates have a great influence on maize ontogeny. This experiment was carried out to evaluate the phenological development of three maize hybrids, at three sowing dates. The experiment was carried out at the Depressão Central region of the state of Rio Grande do Sul-Brazil during 2000/
2001 grows season. The single-cross very early hybrid Pioneer $32 R 21$, the single-cross early hybrid Dekalb 214, and the doublecross normal hybrid Agroceres 1051 were evaluated at 08/22/ 2000 (early), 10/31/2000 (intermediate) and at 01/25/2001 (delayed) sowing dates, with no supplemental irrigation. All hybrids presented shorter developmental subperiods when sowing was delayed. Tassel and ear differentiation occurred, respectively, in the stages of 6 to 7 and 10 to 11 completely expanded leaves, regardless of hybrid cycle and sowing date. The highest leaf emission rate occurred when very early hybrid was sown in October. Delaying sowing resulted in a reduction of leaf area per plant mainly in early hybrids. Number of spikelets per ear, grain yield and grain weight were generally higher in October than in the other two sowing dates.

Key words: Zea mays, cultural practices, phenology.

\section{INTRODUÇÃO}

Em regiões de clima subtropical, os fatores ambientais, principalmente as variações na disponibilidade térmica e de radiação solar, exercem grande influência sobre o desenvolvimento fenológico do milho. A temperatura do ar é o elemento meteorológico que melhor explica a duração dos períodos de desenvolvimento do milho, havendo relação linear entre a duração destes períodos e o desenvolvimento da planta (LOZADA et al., 1999).

As variações nos fatores ambientais determinam a escolha da época de semeadura do milho. A época preferencial de semeadura é aquela que faz

\footnotetext{
1Engenheiro Agrônomo, Mestrando do Programa de Pós-graduação em Fitotecnia, Departamento de Plantas de Lavoura, Faculdade de Agronomia (FA), Universidade Federal do rio Grande do Sul (UFRGS). Bolsista da Coordenação de Aperfeiçoamento de Pessoal de nível Superior (CAPES). E-mail: everton_forsthofer@hotmail.com

${ }^{2}$ Engenheiro Agrônomo, PhD, Professor Adjunto, Departamento de Plantas de Lavoura, FA, UFRGS, Pesquisador do Conselho Nacional de desenvolvimento Científico e Tecnológico (CNPq). Av. Bento Gonçalves, 7712. 91501-970, Porto Alegre-RS. Email: paulo.silva@ufrgs.br. Autor para correspondência.

${ }^{3}$ Engenheiro Agrônomo, Dr, Desenvolvimento de Produtos, Syngenta Seeds Ltda.

${ }^{4}$ Acadêmico de Graduação em Agronomia-UFRGS. Bolsista de iniciação científica do CNPq.

${ }^{5}$ Engenheiro Agrônomo, MSc, Doutorando do Programa de Pós-graduação em Fitotecnia, Departamento de Plantas de Lavoura, FA,UFRGS. Bolsista do CNPq.
} 
coincidir a maior área foliar por planta com os dias mais longos do ano, quando não há limitação hídrica (INDICAÇÕES, 2001). Esta coincidência normalmente ocorre com a semeadura do milho no mês de outubro. Quando esta cultura é semeada no cedo (agosto/ setembro) ou no tarde (dezembro/janeiro), há redução na produção de grãos por planta, em relação à semeadura realizada em outubro. Este decréscimo está associado aos efeitos que a temperatura do ar e a radiação solar exercem sobre o desenvolvimento das plantas, afetando, em consequiência, a formação e a expressão dos componentes do rendimento (SILVA \& ARGENTA, 2000).

Quando o meristema apical está abaixo da superfície do solo, a temperatura do solo é o principal fator determinante da taxa de desenvolvimento do milho. Após este estádio, a temperatura do ar e a radiação solar são os principais fatores que influenciam a fenologia e o desenvolvimento da cultura (STONE et al., 1999). Ao semear o milho antes da época preferencial, há redução na taxa de crescimento e aumento na duração dos subperíodos de desenvolvimento, ocorrendo o contrário com a semeadura no tarde (NOLDIN, 1985).

No Rio Grande do Sul, tanto a antecipação como o atraso da época de semeadura do milho são práticas de manejo comumente empregadas pelos agricultores. A antecipação da semeadura é realizada para evitar a coincidência do período crítico da cultura (floração e enchimento de grãos) com o período mais provável de ocorrência de déficit hídrico, minimizando, assim, a redução de rendimento de grãos. Por outro lado, o atraso da época de semeadura verifica-se nas pequenas propriedades, principalmente para que o milho seja cultivado em sucessão a outras culturas de verão, como fumo e feijão, que tem maior importância econômica para os agricultores.

A caracterização das modificações fenológicas que ocorrem na planta de milho em épocas contrastantes de semeadura é importante para definir a adoção de práticas culturais, visando a maximização do rendimento de grãos em cada época. Assim, esse trabalho teve por objetivo avaliar o efeito de três épocas de semeadura sobre o desenvolvimento fenológico de três híbridos de milho, na região fisiográfica da Depressão Central do Rio Grande do Sul.

\section{MATERIAL E MÉTODOS}

O experimento foi conduzido a campo, no município de Porto Alegre, localizado a $30^{\circ} 02$ ' $15^{\prime \prime}$ de latitude sul e a $51^{\circ} 13$ ' 13 " de longitude oeste, região fisiográfica da Depressão Central do estado do Rio
Grande do Sul, no ano agrícola 2000/2001. O solo da área pertence à unidade de mapeamento Vacacaí, sendo classificado como Planosolo (EMBRAPA, 1999). O clima da região é classificado por Köppen como subtropical úmido, situado na transição entre os tipos fundamentais

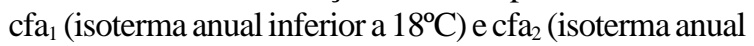
superior a $18^{\circ} \mathrm{C}$ ). $\mathrm{O}$ experimento foi conduzido sob condições naturais de precipitação pluvial.

Foi testado o híbrido simples de milho Pioneer 32R21 (P 32R21), de ciclo superprecoce, com estatura de planta média de $212 \mathrm{~cm}$ e grãos alaranjados semiduros (INDICAÇÕES, 2001), o híbrido simples Dekalb 214 (DKB 214), de ciclo precoce, com estatura média de planta de $199 \mathrm{~cm}$ e grãos amarelos semiduros, e o híbrido duplo Agroceres 1051 (AG 1051), de ciclo normal, com estatura média de planta de $227 \mathrm{~cm}$ e grãos amarelos dentados. Os híbridos foram testados em três épocas, 22 de agosto de 2000 (cedo), 31 de outubro de 2000 (intermediária) e 25 de janeiro de 2001 (tarde). O delineamento experimental utilizado foi o de blocos casualizados, com quatro repetições.

$\mathrm{O}$ experimento foi instalado no sistema de semeadura convencional, dois dias após o preparo do solo. Conforme análise realizada, aplicaram-se 2,5 $\mathrm{tha}^{-1}$ de calcário, incorporado ao solo em toda área experimental, um mês antes da primeira época de semeadura. A adubação de base foi realizada em linha, por ocasião da semeadura, com $25 \mathrm{~kg} \mathrm{ha}^{-1}$ de $\mathrm{N}, 150 \mathrm{~kg}$ ha $^{-1}$ de $\mathrm{P}_{2} \mathrm{O}_{5}$ e $75 \mathrm{~kg} \mathrm{ha}^{-1}$ de $\mathrm{K}_{2} \mathrm{O}$. A adubação nitrogenada de cobertura foi dividida em quatro doses iguais de $50 \mathrm{~kg} \mathrm{ha}^{-1} \mathrm{de} \mathrm{N}$, aplicando-se quando as plantas estavam nos estádios de 3-4, 6-7, 10-11 folhas completamente desenvolvidas e no espigamento, conforme escala de RITCHIE \& HANWAY (1993), utilizando-se a uréia como fonte.

A semeadura foi realizada manualmente, objetivando uma densidade de 60.000 plantas $\mathrm{ha}^{-1}$, colocando-se três a quatro sementes por cova. Aos 14 dias após a emergência, foi realizado desbaste. As parcelas constaram de seis linhas de $6 \mathrm{~m}$ de comprimento, espaçadas em $0,7 \mathrm{~m}$ entre si.

As determinações realizadas foram: duração dos subperíodos de desenvolvimento semeadura-emergência, emergência-diferenciação do pendão, emergência-diferenciação da espiga, emergência-pendoamento, emergência-espigamento, emergência-grãos em massa mole, emergência grãos em massa dura e emergência-maturação fisiológica; número de folhas completamente desenvolvidas, nas diferenciações do pendão e da espiga; número potencial de espiguetas por espiga; taxa de emissão de folhas e área foliar por planta, no espigamento, e número de espigas por planta, número de grãos por 
espiga, peso do grão e rendimento de grãos, na maturação de colheita.

Considerou-se a emergência do milho quando $75 \%$ das plantas estavam com o coleóptilo visível na superfície do solo. As diferenciações do pendão e da espiga foram realizadas em laboratório, sendo considerado diferenciado o pendão quando da elongação da gema apical e na base desta apareceram protuberâncias que originaram as ramificações do pendão. Já a diferenciação da espiga superior foi considerada quando da elongação da gema lateral e nesta apareceram algumas projeções (futuras espiguetas) separadas por sulcos transversais. O pendoamento e o espigamento foram determinados a campo, sendo considerado atingido o pendoamento quando em $75 \%$ das plantas o pendão estava totalmente visível e o espigamento quando $75 \%$ das plantas apresentavam estigmas visíveis.

O número potencial de espiguetas por espiga foi determinado na espiga superior, entre os estádios de pendoamento e espigamento, através da contagem do número de espiguetas por espiga. A taxa de emissão de folhas foi obtida pela divisão do número de folhas pela duração do período em dias e a área foliar pelo somatório da área foliar de cada folha viva (NOLDIN, 1985).

Os dados foram submetidos à análise de variância, e quando significativo a 5\% pelo teste $\mathrm{F}$, as médias dos tratamentos foram comparadas pelo teste de Tukey, a 5\% de probabilidade, com o uso do programa SAS, procedimento MIXED. Primeiro analisaram-se as épocas individualmente e, após, de forma conjunta, considerando a época de semeadura como fator aleatório.

\section{RESULTADOS E DISCUSSÃO}

A radiação solar global média durante a estação de crescimento 2000/2001 demonstra que, de outubro a março, a radiação solar foi superior a $400 \mathrm{cal}$ $\mathrm{cm}^{-2} \mathrm{dia}^{-1}$, e a máxima radiação solar ocorreu no terceiro decêndio de dezembro (Figura 1A). Já a temperatura média do ar foi superior a $20^{\circ} \mathrm{C}$ no período compreendido entre novembro de 2000 e março de 2001, sendo as máximas temperaturas médias verificadas no terceiro decêndio de fevereiro (Figura 1B).

A temperatura do solo a $5 \mathrm{~cm}$ de profundidade elevou-se de $13,7^{\circ} \mathrm{C} \mathrm{a} 27^{\circ} \mathrm{C}$ com o atraso da semeadura de agosto para janeiro (Figura 1B). A redução na duração do subperíodo semeaduraemergência em aproximadamente 15 dias à medida que foi retardada a semeadura de agosto para janeiro, pode ser atribuída ao incremento na temperatura do solo
(Figura 2). Conforme BERLATO et al. (1984), para cada $1^{\circ} \mathrm{C}$ de aumento da temperatura do solo ocorre redução de meio dia na duração desse subperíodo. O híbrido de ciclo normal, na semeadura do cedo, apresentou baixa emergência (48\%) devido, provavelmente, a sua maior sensibilidade a baixas temperaturas, já que nas demais épocas a emergência foi similar a dos demais híbridos, demonstrando que é inadequada a utilização de híbridos de ciclo normal em semeaduras de agosto (cedo).

A duração dos subperíodos de desenvolvimento do milho, especialmente no período vegetativo, diminuiu à medida que a semeadura foi atrasada de agosto para janeiro, independente do ciclo do híbrido (Figura 2). Isto se deve ao incremento na temperatura do solo e do ar à medida que se atrasou a semeadura, pois, quando o meristema apical está abaixo da superfície do solo, a temperatura do solo é quem governa o desenvolvimento do milho (STONE et al., 1999) e, quando acima da superfície do solo, a temperatura do ar é quem determina a duração dos subperíodos de desenvolvimento em híbridos considerados insensíveis ao fotoperíodo (LOZADA et al., 1999). Conforme STONE et al. (1999), para cada $1^{\circ} \mathrm{C}$ de elevação na temperatura do ar há redução de cinco a seis dias na duração do período compreendido entre emergência e espigamento. Entre híbridos, verificou-se que a duração dos subperíodos de desenvolvimento foi maior no de ciclo normal em relação ao de ciclo precoce e deste para o superprecoce, nas três épocas de semeadura.

Nas diferenciações do pendão e da espiga, o número de folhas completamente desenvolvidas variou pouco em função de época de semeadura e ciclo do híbrido de milho (Tabela 1). Na diferenciação do pendão, o número de folhas variou de 6,0 a 7,0 e na diferenciação da espiga o número de folhas variou de 10,0 a 10,9. Estes resultados estão de acordo com NOLDIN (1985), que verificou que as diferenciações do pendão e da espiga ocorreram, respectivamente com 6,9 a 8,1 e com 9,2 a 12,1 folhas desenvolvidas. Assim sendo, pode-se afirmar que o momento da diferenciação destas estruturas reprodutivas está associado ao número de folhas desenvolvidas. Portanto, a aplicação de práticas culturais com o objetivo de potencializar o rendimento de grãos deverá ser baseada nos estádios fenológicos da cultura, independente do híbrido e da época de semeadura.

A taxa de emissão de folhas foi maior na semeadura de outubro e no híbrido de ciclo superprecoce, em relação a das demais épocas e híbridos, respectivamente (Tabela 2). Aárea foliar foi similar nas semeaduras de agosto e outubro, sendo estas superiores à obtida na semeadura do tarde (Tabela 2). Esperava-se que o milho semeado em 

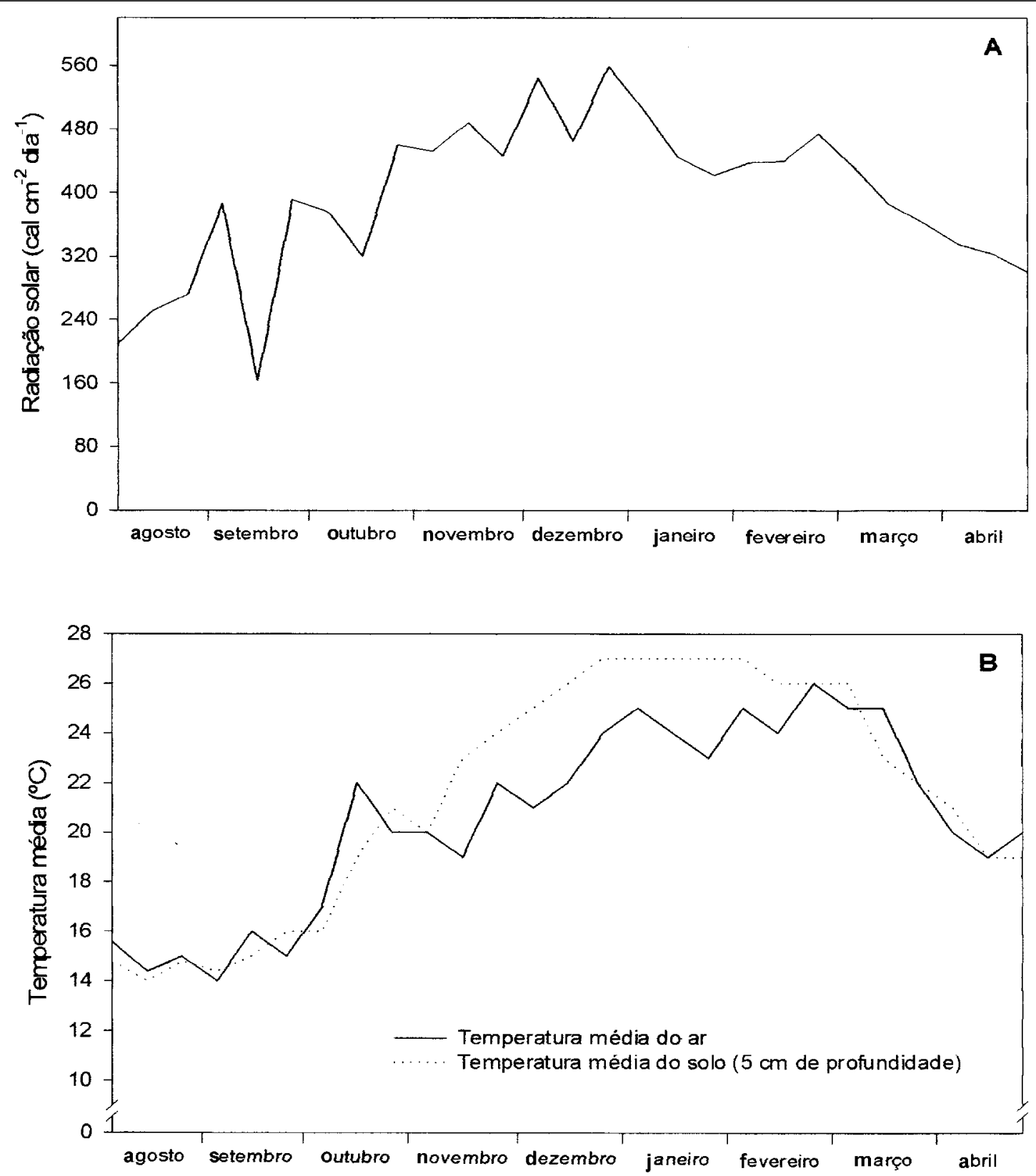

Dados climáticos da Estação Experimental de Agronomia, Universidade Federal do Rio Grande do Sul, Eldorado do Sul - RS

Figura 1 - Radiação solar global (A) e temperatura média do ar e do solo desnudo a $5 \mathrm{~cm}$ de profundidade (B) no período compreendido entre agosto de 2000 a abril de 2001. Eldorado do Sul-RS.

outubro apresentasse maior área foliar do que o implantando em agosto, devido às condições mais favoráveis de ambiente (temperatura e radiação) naquela época. Isto não ocorreu, provavelmente devido ao déficit hídrico verificado de novembro a janeiro (dado não apresentado), o qual reduziu a expansão foliar na semeadura de outubro. Aárea foliar diminuiu com a redução do ciclo do híbrido, nas três épocas de semeadura (Tabela 2).

Quanto ao número potencial de espiguetas por espiga, os dados obtidos estão de acordo com o relatado por ALDRICH \& LENG (1972), 


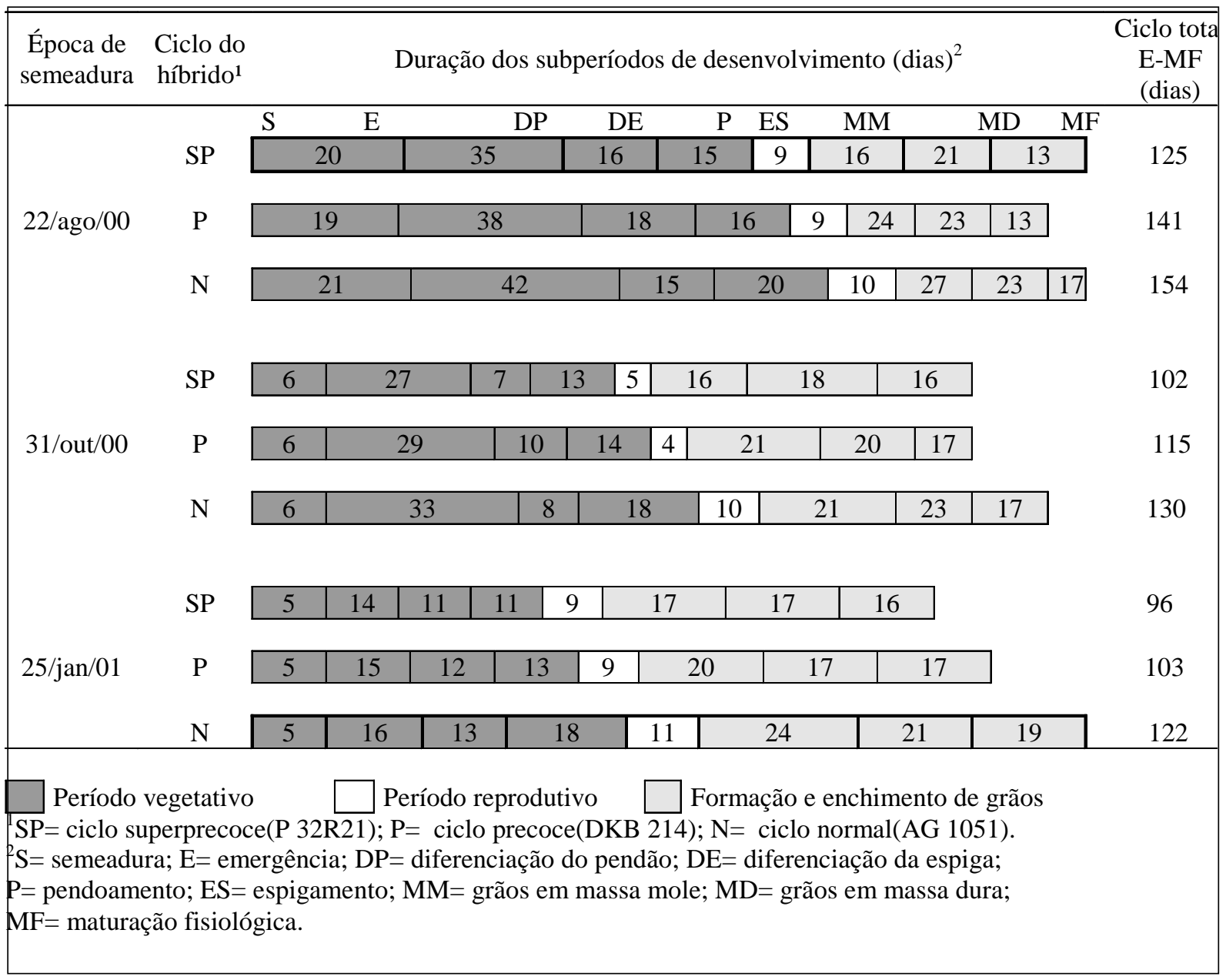

Figura 2 - Duração dos subperíodos de desenvolvimento e do ciclo total de três híbridos de milho, em três épocas de semeadura. Porto Alegre-RS, 2000/2001.

Tabela 1 - Número de folhas completamente desenvolvidas, em dois estádios fenológicos, de três híbridos de milho, em três épocas de semeadura. Porto Alegre-RS, 2000/2001.

\begin{tabular}{cccc}
\hline \multirow{2}{*}{$\begin{array}{c}\text { Época de } \\
\text { semeadura }\end{array}$} & $\begin{array}{c}\text { Ciclo do } \\
\text { híbrido }\end{array}$ & \multicolumn{2}{c}{$\begin{array}{c}\text { Número de folhas } \\
\text { desenvolvidas }^{2}\end{array}$} \\
\cline { 3 - 4 } & & DP & DE \\
\hline 22/Ago/00 & SP & 6,1 & 10,0 \\
& $\mathrm{P}$ & 6,3 & 10,4 \\
31/Out/00 & $\mathrm{N}$ & 6,8 & 10,9 \\
& $\mathrm{SP}$ & 6,4 & 10,2 \\
& $\mathrm{P}$ & 6,8 & 10,6 \\
25/Jan/00 & $\mathrm{N}$ & 7,0 & 10,7 \\
& $\mathrm{SP}$ & 6,0 & 10,0 \\
& $\mathrm{P}$ & 6,2 & 10,2 \\
& $\mathrm{~N}$ & 6,7 & 10,5 \\
\hline
\end{tabular}

${ }^{1} \mathrm{SP}=$ ciclo superprecoce $(\mathrm{P}$ 32R21 $) ; \mathrm{P}=$ ciclo precoce $(\mathrm{DKB}$ 214); N= ciclo normal(AG 1051).

²P= diferenciação do pendão; $\mathrm{DE}=$ diferenciação da espiga. que se situa ao redor de 700 a 1000 espiguetas por espiga. O número potencial de espiguetas por espiga foi menor na semeadura de janeiro do que nas demais épocas de semeadura, com exceção do híbrido de ciclo normal, para o qual não houve diferença entre as épocas de semeadura de outubro e janeiro. Esta redução na semeadura do tarde, provavelmente, está associada à menor disponibilidade de fotoassimilados e aos maiores custos respiratórios, devido a radiação solar desta época encontrar-se em fase decrescente e às altas temperaturas incrementarem as perdas respiratórias (CIRILO et al., 1994). A menor redução no número potencial de espiguetas por espiga para o híbrido de ciclo normal na semeadura de janeiro, provavelmente, está relacionada com a maior diferença temporal entre a diferenciação da espiga e o pendoamento (18 dias) (Figura 2) o que reduziu o nível de protandria, evidenciando ser os híbridos de ciclo normal uma 
Tabela 2 - Taxa de emissão de folhas e área foliar de três híbridos de milho, em três épocas de semeadura. Porto Alegre-RS, $2000 / 2001$.

\begin{tabular}{|c|c|c|c|c|}
\hline \multirow{2}{*}{$\begin{array}{l}\text { Ciclo do } \\
\text { híbrido }^{1}\end{array}$} & \multicolumn{3}{|c|}{ Época de semeadura } & \multirow[b]{2}{*}{ Média } \\
\hline & 22/AGO/00 & 31/OUT/00 & 25/JAN/00 & \\
\hline \multicolumn{5}{|c|}{ Taxa de emissão de folhas (folhas dia $^{-1}$ ) } \\
\hline SP & 0,17 & 0,23 & 0,19 & $0,19 \mathrm{a}$ \\
\hline $\mathrm{P}$ & 0,15 & 0,21 & 0,18 & $0,18 \mathrm{~b}$ \\
\hline $\mathrm{N}$ & $--^{2}$ & 0,19 & 0,16 & $0,18 \mathrm{~b}$ \\
\hline \multirow[t]{2}{*}{ Média } & C $0,16^{*}$ & A 0,21 & B 0,18 & \\
\hline & & $\mathrm{CV}(\%)$ & 3,33 & \\
\hline \multicolumn{5}{|c|}{------- Área foliar $\left(\mathrm{cm}^{2}\right)$------- } \\
\hline SP & A 5886 b & A 5912 c & B 3968 b & \\
\hline $\mathrm{P}$ & A 6743 a & A 6998 b & B $4288 \mathrm{ab}$ & \\
\hline \multirow[t]{2}{*}{$\mathrm{N}$} & $--^{2}$ & A 8014 a & B 4664 a & \\
\hline & \multicolumn{2}{|r|}{$\mathrm{CV}(\%)$} & 3,97 & \\
\hline
\end{tabular}

${ }^{1} \mathrm{SP}=$ ciclo superprecoce $(\mathrm{P} 32 \mathrm{R} 21) ; \mathrm{P}=$ ciclo precoce $(\mathrm{DKB} 214) ; \mathrm{N}=$ ciclo normal (AG 1051).

2 Não avaliada, devido à baixa emergência.

* Médias antecedidas pela mesma letra maiúscula na linha e seguidas pela mesma letra minúscula na coluna não diferem entre si pelo teste de Tukey, em nível de $5 \%$ de probabilidade.

boa alternativa para semeaduras em janeiro (tarde). Para o híbrido de ciclo precoce, o número de espiguetas por espiga diminuiu à medida que se atrasou a semeadura. Já para os demais híbridos, obteve-se maior número de espiguetas na semeadura de outubro, apesar de não haver diferença significativa entre esta e a época do tarde para o híbrido de ciclo normal e do cedo para o híbrido de ciclo superprecoce (Tabela 3 ).

O rendimento de grãos foi maior na semeadura de outubro em relação ao da semeadura de agosto e esta em relação à de janeiro, independente do ciclo do híbrido (Tabela 3) devido, provavelmente, às melhores condições de temperatura e radiação solar verificadas na semeadura de outubro. Na semeadura do tarde, os rendimentos de grãos foram inferiores ao das demais épocas, principalmente, devido ao menor peso de grão nesta época (Tabela 3). Conforme KINIRY \& OTEGUI (2000), o menor peso de grão no tarde pode ser atribuído à menor radiação solar desta época em relação a das demais e também ao fato de que a radiação encontrase em fase decrescente, reduzindo por conseqüência a produção de fotoassimilados e a área foliar (Tabela 2). O número de espigas por planta não variou em função de híbridos, sendo inferior na época do tarde em relação ao das demais épocas testadas (Tabela 3), devido ao menor acúmulo de fotoassimilados (KINIRY \& OTEGUI, 2000) e o maior custo respiratório na época do tarde devido às elevadas temperaturas do ar (CIRILO et al., 1994).
O número de grãos por espiga foi maior na semeadura de outubro, com exceção do híbrido de ciclo superprecoce em agosto e do híbrido de ciclo normal em janeiro (Tabela 3), provavelmente devido às melhores condições ambientais verificadas na semeadura de outubro e também porque os híbridos de ciclo superprecoce são mais adaptados a temperaturas amenas e os de ciclo normal a temperaturas mais elevadas. Verificou-se que o número de grãos por espiga foi aproximadamente $30 \%$ inferior ao número potencial de espiguetas diferenciadas, na média das três épocas de semeadura e dos três híbridos testados. Esta redução provavelmente está associada a característica protândrica do milho, que pode ser visualizada pela grande diferença temporal entre as diferenciações do pendão e da espiga e pelo curto espaço de tempo entre a diferenciação da espiga e o pendoamento (Figura 2).

\section{CONCLUSÕES}

A duração dos subperíodos de desenvolvimento do milho diminui com o atraso da semeadura de agosto para janeiro na Depressão Central do RS, independente do ciclo do híbrido. Já as diferenciações do pendão e da espiga ocorrem, respectivamente, nos estádios de 6 a 7 e de 10 a 11 folhas, independente do ciclo do híbrido e da época de semeadura. A taxa de emissão de folhas é maior na semeadura de outubro e no híbrido superprecoce, respectivamente, em relação a das semeaduras de 
Tabela 3- Número potencial de espiguetas por espiga, componentes do rendimento e rendimento de grãos de três híbridos de milho, em três épocas de semeadura. Porto Alegre-RS, 2000/2001.

\begin{tabular}{|c|c|c|c|c|c|}
\hline \multicolumn{2}{|c|}{ Ciclo do híbrido ${ }^{1}$} & \multicolumn{4}{|c|}{ Época de semeadura } \\
\hline & & 22/AGO/00 & $31 / \mathrm{OUT} / 00$ & 25/JAN/00 & Média \\
\hline \multicolumn{6}{|c|}{ Espiguetas por espiga $\left(\mathrm{n}^{\circ}\right)$} \\
\hline SP & & A $844 a^{*}$ & A 855 a & B $649 \mathrm{ab}$ & \\
\hline $\mathrm{P}$ & & A 800 a & B 694 b & $\mathrm{C} 625 \mathrm{~b}$ & \\
\hline $\mathrm{N}$ & & $--^{2}$ & A 739 b & A 706 a & \\
\hline $\mathrm{CV}(\%)$ & 6,1 & & & & \\
\hline \multicolumn{6}{|c|}{ Grãos por espiga $\left(n^{\circ}\right)$} \\
\hline SP & & A 559 a & A 575 a & B 435 a & \\
\hline $\mathrm{P}$ & & B $457 \mathrm{~b}$ & A 559 a & B 461 a & \\
\hline $\mathrm{N}$ & & $--^{2}$ & A 459 b & A 476 a & \\
\hline $\mathrm{CV}(\%)$ & 5,6 & & & & \\
\hline \multicolumn{6}{|c|}{ Peso do grão (mg) } \\
\hline SP & & A 33,5 a & A 34,5 a & B $14,7 \mathrm{c}$ & \\
\hline $\mathrm{P}$ & & A 32,4 a & A $32,7 \mathrm{ab}$ & B $16,7 \mathrm{~b}$ & \\
\hline $\mathrm{N}$ & & $--^{2}$ & A $32,0 \mathrm{~b}$ & B 23,4 a & \\
\hline $\mathrm{CV}(\%)$ & 6,7 & & & & \\
\hline \multicolumn{6}{|c|}{ Espigas por planta $\left(\mathrm{n}^{\circ}\right)$} \\
\hline SP & & 1,06 & 1,01 & 0,96 & $1,01^{\mathrm{ns}}$ \\
\hline $\mathrm{P}$ & & 1,04 & 1,04 & 0,95 & 1,01 \\
\hline $\mathrm{N}$ & & $--^{2}$ & 1,05 & 1,00 & 1,03 \\
\hline Média & & A 1,05 & A 1,03 & B 0,97 & \\
\hline $\mathrm{CV}(\%)$ & 2,1 & & & & \\
\hline \multicolumn{6}{|c|}{------ Rendimento de grãos $\left(\mathrm{t} \mathrm{ha}^{-1}\right)$------ } \\
\hline SP & & B 8,90 a & A $11,38 \mathrm{a}$ & C $3,78 \mathrm{~b}$ & \\
\hline $\mathrm{P}$ & & B 7,44 a & A 10,95 a & $\mathrm{C} 4,55 \mathrm{~b}$ & \\
\hline $\mathrm{N}$ & & $--^{2}$ & A 8,85 b & B 6,44 a & \\
\hline $\mathrm{CV}(\%)$ & 12,7 & & & & \\
\hline
\end{tabular}

$1 \mathrm{SP}=$ ciclo superprecoce (P 32R21); $\mathrm{P}=$ ciclo precoce (DKB 214); $\mathrm{N}=$ ciclo normal (AG 1051).

2 Não avaliada, devido à baixa emergência.

* Médias antecedidas pela mesma letra maiúscula na linha e seguidas pela mesma letra minúscula na coluna não diferem entre si pelo teste de Tukey, ao nível de 5\% de probabilidade.

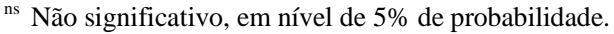

agosto e janeiro e os híbridos de ciclo precoce e normal. A área foliar por planta é menor na semeadura de janeiro, em relação às de agosto e outubro, sendo incrementada à medida que aumenta o ciclo do híbrido. A semeadura de outubro propicia maior rendimento de grãos do que as semeaduras de agosto e janeiro.

\section{REFERÊNCIAS BIBLIOGRÁFICAS}

ALDRICH, S.R.; LENG, E.R. Modern corn production. Illinois : Few Corp Printed, 1972. p.172.

BERLATO, M.; MATZENAUER, R.; SUTILI, V.R. Relação entre temperatura e o aparecimento de fases fenológicas do milho. Agronomia Sulriograndense, Porto Alegre, v.20, p.111-132, 1984.
CIRILO, A.G.; ANDRADE, F.H. Sowing date and maize productivity: II. Kernel number determination. Crop Science, Madison, v.34, p.1044-1046, 1994.

EMBRAPA-CENTRO NACIONAL DE PESQUISA DE SOLOS. Sistema brasileiro de classificação de solos. Rio de Janeiro : Embrapa, 1999. 412p.

INDICAÇÕES TÉCNICAS PARA A CULTURA DO MILHO NO RS. Porto Alegre : FEPAGRO; EMATER/RS; FECOAGRO/ RS, 2001. n.7, ago. 196p.

KINIRY, J.R.; OTEGUI, M.E. Processes affecting maize grain yield potential in temperate conditions. In: OTEGUI, M.E.; SLAFER, G.A. Physiological bases for maize improvement. New York: Haworth, 2000. Cap.3, p.3145 .

Ciência Rural, v.34, n.5, set-out, 2004. 
LOZADA, B.I.; ANGELOCCI, L.R. Efeito da temperatura do ar e da disponibilidade hídrica do solo na duração de subperíodos e na produtividade de um híbrido de milho. Revista Brasileira de Agrometeorologia, Santa Maria, v.7, n.1, p.37-43, 1999.

NOLDIN, J.A. Rendimento de grãos, componentes do rendimento e outras características de planta de três cultivares de milho em duas épocas de semeadura. 1985. 149f. Dissertação (Mestrado em Fitotecnia) - Curso de Pós-graduação em Agronomia, UFRGS.

RITCHIE, S.W.; HANWAY, J.J. How a corn plant develops.
Iowa State University. Special report n. 48, Ames, 1993. Online. Disponível na Internet www.maize.agron.iastate.edu/ corngrows.html.

SILVA, P.R.F. da; ARGENTA, G. Ecofisiologia e fenologia das culturas do milho e do sorgo. In: PARFITT, J.M.B. (coord.) Produção de milho e sorgo na várzea. Pelotas : Embrapa Clima Temperado, 2000. p.07-18.

STONE, P.J.; SORENSEN, I.B.; JAMIESON, P.D. Effect of soil temperature on phenology, canopy development, biomass and yield of maize in a cool-temperate climate. Field Crops Research, Hastings, v.63, p.169-178, 1999. 